\title{
The Albian message
}

\section{A blast from the past.}

\section{Oliver Morton}

\section{To: Eva P.}

From: Stefan K.

Re: Sample handling facility

March 4, 2047

I thought I ought to put into writing my concerns over the sample-return facility for Odyssey. I think that relying on the mothballed Mars Sample Return lab at Ames is dangerously complacent. It is simply not flexible enough, or big enough, for what I think we should be expecting.

I appreciate that I am in a minority on this, and that the consensus is that we will be dealing with non-biological artefacts. And I don't want to sound like the people from AstraRoche slipped some egopoietin into my drink during that trip to Stockholm last November. But my minority views have been pretty well borne out throughout this whole story. Back when Suzy and Sean had more or less convinced the world that the trinity sequences in the Albian message referred to some sort of mathematico-philosophical doctrine possibly based on an analogy to the aliens' purported trisexual reproductive system - and everyone in SETI was taking a crash course in genome analysis, I had to pull in every favour I was owed to get the Square Kilometre Array used as a planetary radar and scanned over the Trojan asteroids. If I hadn't done that we wouldn't even know about the Pyramid, let alone be sending Odyssey there.

I'm not daiming I understand the Albians' minds better than anyone else; I haven't got any more of the message in my DNA than anyone else has. And it's always been my position that we should read as little into that message as possible. I remain convinced that looking for descriptions of their philosophy or lifestyle or even provenance is pointless. The more I look at the increasingly meaningless analyses that the increasingly intelligent AIs produce, the more I think that the variations between phyla are effectively random and that the message from the aliens tells us almost nothing except that there's a radar-reflecting tetrahedron $\pi / 3$ behind Jupiter that they think we may find interesting.

Everyone assumes that if it hadn't been for the parts of the message lost in the K/T the 'residual variant sequences' would be seen to add up to some great big life-theUniverse-and-everything revelation. And because they think such a revelation once existed, they expect to see it carved into the palladium walls of the Pyramid. But if the aliens who visited Earth, and left their messages in the genomes of more or less everything on the planet, had wanted to tell us something more about themselves, they could have made the messages a lot bigger and built in more redundancy across phylum space; there's no shortage of junk DNA to write on. The point is, they didn't choose to leave big messages - just a simple signpost.

The reason I was able to get the SKA people to find the Pyramid was that they knew I'd thought about SETI a lot. But these days people tend to forget that I was always something of a sceptic. What could a bunch of aliens tell us about themselves, or the Universe, that would matter? Especially if, like the Albians, they sent, or rather left, the message 100 million years ago? Well, in the case of the Albians, there's one type of knowledge they could be fairly sure that anyone who eventually evolved sequencing technology on Earth pretty much had to be interested in. And it's something that, by definition, is too big to fit into the spare bits of a genome.

I appreciate that everyone on the project now has a lot of faith in what we can do on the fly, especially in terms of recording and analysing information. I'll admit that when we started I really didn't think that the lost craft of human spaceflight would be so easy to reinvent. It still strikes me as remarkable that none of us realized how much could be achieved by leaving a technical problem to one side and concentrating on other things for a few decades before coming back to it with new technologies. But the problem with the samplereturn facility won't just be one of technology. It's going to be one of size.

You see, extinctions aren't the noise in the message. They're the reason for the message. The one thing the Albians knew they could do for whoever would end up reading their message was store up some of the biodiversity that would inevitably be whittled away over time. When Odyssey gets to the Trojan Pyramid, I don't expect it to find any more information about the Albians than we have already. I do expect a biosphere's worth of well-preserved biological samples from the mid-Cretaceous. Not just genomes, but whole samples. Sudarat and her boys are going to come home with a hold full of early angiosperms and dinosaur eggs. We need to be ready. Oliver Mortonis a contributing editor at Wired and the author of Mapping Mars: Science, Imagination and the Birth of a World (2002) and the forthcoming Eating the Sun: How Plants Powerthe Planet. He does not normally knowingly commit fiction. He took over as Nature's Chief News and Features Editor lastmonth. 